\title{
The Feasibility of Controlled Environment in Horticulturally Poor Region: The Case of New Brunswick in Canada
}

\author{
Sylvain Charlebois ${ }^{1}$, Shannon Faires ${ }^{1}$, Janet Music ${ }^{1} \&$ Kent Williams ${ }^{1}$ \\ ${ }^{1}$ Agri-food Analytics LAB, Dalhousie University, Canada \\ Correspondence: Sylvain Charlebois, Agri-food Analytics LAB, Dalhousie University, Canada. E-mail: \\ sylvain.charlebois@dal.ca
}

Received: May 9, 2021

Accepted: July 20, $2021 \quad$ Online Published: July 23, 2021

doi:10.5539/jfr.v10n4p33

URL: https://doi.org/10.5539/jfr.v10n4p33

\begin{abstract}
More than $90 \%$ of the money spent on food in the Canadian province of New Brunswick was spent on food that was imported to the province from either other provinces or out of the country. The feasibility of controlled environment agriculture in the Canadian province of New Brunswick depends on a large variety of factors, some of which have no available data. Few studies have looked at this issue, including consumers' willingness to pay for locally grown produce in that region. The study aims at understanding how agriculture can serve the region differently to increase its food autonomy and how consumers would be receptive to more locally grown produce. From the information in the survey conducted, unless CEA (Controlled Environment Agriculture) crops can compete with conventionally grown and imported alternatives pricewise, it could face many issues in New Brunswick and Canada considering the economic uncertainties surrounding COVID-19. Canadians were also surveyed specifically about paying a premium for food that they considered local, not necessarily Canada as a whole, and many of the larger regions in Canada, such as Ontario and Quebec, consider food grown within their region as local - a definition which would not include New Brunswick.
\end{abstract}

Keywords: food security, controlled-environment agriculture, horticulture, greenhouses, vertical farms

\section{Introduction}

About $90 \%$ of the money spent on food in the Canadian province of New Brunswick was spent on food that was imported to the province from either other provinces or out of the country (Haghiri et. al., 2009). In a situation such as COVID-19, this can post potential problems if there are any disruptions to cross-border shipping. CEA (Controlled Environment Agriculture) could allow for New Brunswick to grow fresh produce outside of the regular growing season. However, greenhouses have upfront costs involved, and may potentially be more expensive than regular farming operations. Many CEA operations are built in cities, necessitating a larger cost for land, and many CEA operations also require heating and electricity costs (Ceres, 2020; Laate, 2013). These additional costs would need to be recouped somehow, and may increase the cost of produce for consumers, impacting whether consumers would be willing to pay for them (Dieterle, 2016; Giraud, 2021). Consumer attitudes towards CEA crops will also impact whether customers are willing to buy the products and must also be considered (Walters et al., 2021).

Many studies have been conducted on consumer willingness to pay (WTP) for food, but only one has been conducted in New Brunswick, which was done in 2009, and focused on customer WTP for integrated pest management (Haghiri et. al., 2009). In the study by Haghiri et. al. (2009), almost all respondents would not pay more than $10 \%$ extra for the produce using integrated pest management techniques. There was no available data on New Brunswicker's WTP for local food, nor was there any recent data on their WTP in general, which had likely changed as a result of the pandemic and a variety of other factors since the original study in 2009.

This study aims at understanding the role of CEA and how it supports a broader food autonomy agenda for governments. It also aims to comprehend how CEA-grown produce is perceived by consumers. Consumer attitudes towards CEA agriculture are also important to consider when assessing feasibility. If consumers believe that CEA crops are worse than conventionally grown crops, they will not purchase CEA grown crops when at the grocery store, especially if CEA crops are more expensive than their conventionally grown counterparts. 
This report will present the findings from a survey regarding consumer attitudes towards CEA grown crops and consumer WTP and their implications for the feasibility of CEA agriculture in New Brunswick. It also includes additional considerations with regards to supplier fees, which may impact the cost of all food in certain grocery chains and could have future implications of consumer WTP if their grocery bills become even more expensive.

\subsection{Food Autonomy and Consumer Perception}

Food security is a priority for all countries around the world. In the Western world, food security of often taken for granted (Fieldhouse and Thompson, 2012; Charlebois and Vandertuin, 2021). Becoming more food autonomous is known to be a continuing pursuit for most countries around the world (Benke and Tomkins, 2017; Kolinjivadi, Mendez and Dupras, 2019). Food autonomy is founded on four fundamental concepts: Access for all people to enough quality food and to food resources, at a reasonable cost (Wakefield et al., 2015). Unlike food sovereignty, food autonomy is about producing more food in an open economy which embraces trade. Canada's economy, like many other countries, is trade reliant (Modongo, Oteng and Kulshreshtha, 2018). With efficient distribution systems, underserved markets, or region where the primary production of food is a challenge, can remain food secure (Charlebois and Christensen-Hughes, 2015). Nonetheless, disruption within the supply chain can make that very region more vulnerable, almost instantly (Watts et al., 2015; Power, 2017).

The COVID pandemic had brought an heighten sense of food insecurity in many Canadians (Brady and Brady, 2020). Canada's climate does not allow for domestic agriculture to fully participate in making Canada food anonymous all year round (Zheng, Dixon and Ferguson, 2011; Gomez et al., 2019; Chen et al., 2020). Producing more domestically all year around went from being an after-thought to a political and socio-economical priority during the pandemic for most provinces in Canada, including New Brunswick. One way to achieve such a goal is to build more CEA capacity (Ineck et al., 2020; Miliauskiene et al., 2021). The will to buy locally CEA-grown produce has largely been understudied in a Canadian environment, especially in the context of a pandemic when food security concerns have been acute.

Consumers have often desired locally produced vegetable and fruits, but sales have not always given the same story (Abdullah et al., 2016). Many factors have pushed consumers away from locally grown produce, such as price, availability, and the perception of growing in a greenhouse, or other CEA-type facility (Cavaliere et al., 2014). Some consumers have had concerns about CEA as it may not reconstruct the exact natural environment food has conventional been grown in (Cholette et al., 2013; Shamshiri et al., 2018). Reaction to locally grown produce using new technologies is largely misunderstood in Canada, and the Atlantic region where New Brunswick is located.

\subsection{Methodology}

The participants of this study were randomly recruited across Canada. Even if the study focuses on one province, have data from other provinces would bring perspective on how New Brunswick consumers compare with other Canadians. The selected participants agreed to participate voluntarily only on the criteria of being a consumer in Canada and had to be an adult. The data used in this paper was obtained from a survey on consumer awareness and purchase behavior from an accredited third-party field house which was selected to collect the data for this project. The survey was conducted online, and the sample design allowed it to be representative of the Canadian population, based on age, gender and regional representation.

The survey was composed of questions to assess consumer WTP and attitudes towards CEA grown crops across the country to assess the viability of CEA produce. The survey was sent out in two parts in September 2020. The first part of the survey went out to 7,950 Canadians and the second part surveying 8,124 Canadians, with a total of 10,266 unique users responding to the survey. There was a total of 272 New Brunswickers who answered the survey, with 220 answered the first part and 222 answering the second. For instrument validity, we conducted a pilot-test and made very minor adjustments as a result.

The survey assessed what consumers considered to be local to them in order to better understand what produce people would be more willing to pay a premium on, their attitudes towards CEA crops in order to assess whether or not consumers viewed them positively to determine whether or not consumers would be willing to buy CEA crops, what they considered important when buying produce in order to determine whether or not they are even looking for local food and if there are any factors that could prove prohibitive for CEA crop feasibility, how much extra they would be willing to pay for locally grown produce to determine whether or not it would be feasible with any price discrepancies, their grocery shopping habits in order to see where CEA crops would need to get on the shelves in order to be feasible, and dietary habits as that may impact people's WTP. A copy of the survey questions can be found in Appendix A. 
Caution must be taken with WTP surveys, as consumer habits do not always reflect their responses when they reach the grocery store, and the reality of the price differences is visible. Nevertheless, they can provide valuable indicators and trends particularly when comparing regional differences.

\section{Attitudes towards CEA Crops and WTP}

In order to assess the feasibility of CEA, consumer attitudes towards CEA crops and WTP with regards to these crops must be considered. The survey questioned respondents on the perceived quality and value of CEA crops in relation to their conventionally grown counterparts, what they considered to be important when choosing what fruits and vegetables to buy and asked about their WTP for locally grown fruits and vegetables. This data can help assess whether or not consumers are interested in buying CEA crops, even in the case that they are more expensive than their conventionally grown counterparts. What consumers consider important is also important to consider when assessing feasibility, because while consumers may value locally grown food, they may not be looking for it at the grocery store or consider it important when choosing what produce to purchase. The premium consumers are willing to pay is important because if CEA crops are more expensive than their conventionally grown counterparts, consumers will likely stick to produce within their price range.

\subsection{Attitudes: Canada as a Whole}

Overall, Canadians value produce that they consider local, the definition of which varied by province in the survey. Some respondents considered that anything grown in their region was local while others considered local to be anything grown within their own province. Of survey respondents, $51.6 \%$ either agreed or strongly agreed with the statement "I would pay a premium for off-season fresh produce grown locally in greenhouses (or using other technologies) versus imported alternatives", and $27.4 \%$ of respondents considered CEA grown produce to be better than conventionally grown field crops as opposed to only $9.2 \%$ who considered CEA grown produce to be worse than the conventionally grown alternatives.

\section{How is the quality and value of fruits and vegetables grown in greenhouses or rooftop farms, as compared to conventional land-grown foods? $(n=7950)$}

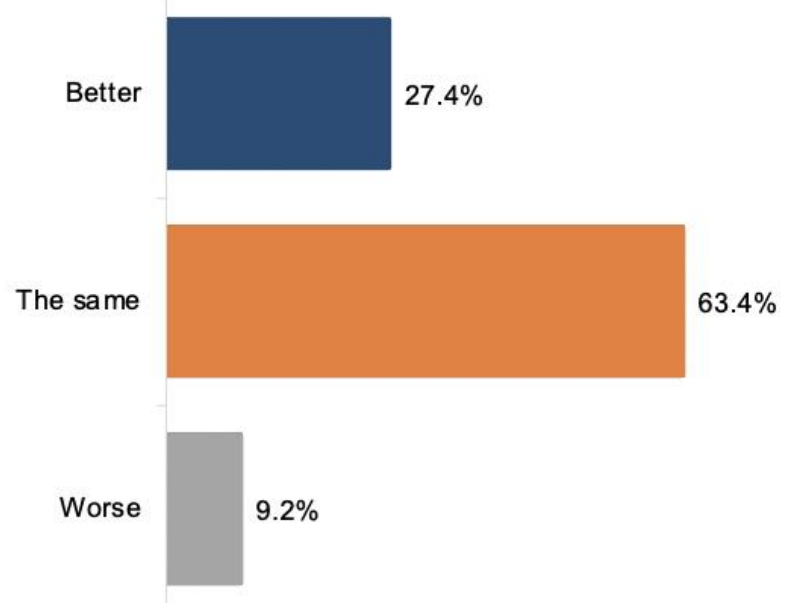

Figure 1. Graph showing Canadian perceptions of CEA grown crops in comparison to conventionally grown crops

When asked about what kind of premium respondents would be willing to pay for locally grown produce, only $20.5 \%$ of respondents said that they would be unwilling to pay any kind of premium at all while $43.3 \%$ of respondents said they would be willing to pay a premium greater than $10 \%$. Overall, Canadians value locally grown produce very highly, and say that they would be willing to pay a premium. However, when asked what they consider to be important when choosing produce at the grocery store, $61.7 \%$ of respondents said that price was an important factor, compared to only $32.3 \%$ saying that where it was produced was important, trailing behind taste at $37.6 \%$. 


\section{Which of the following options are important to you when choosing fresh produce? (Please select all that apply) $(n=7950)$}

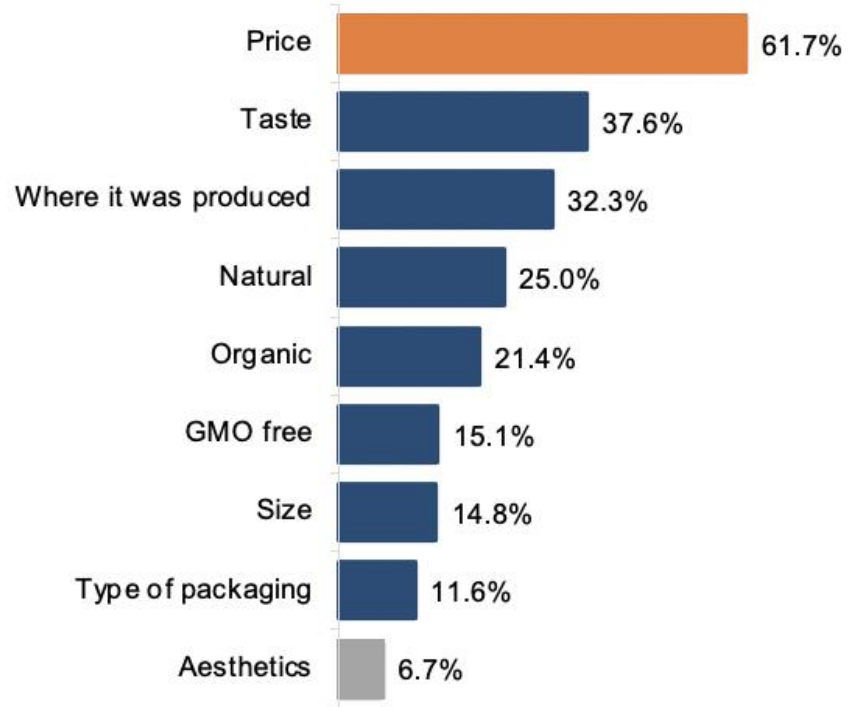

Figure 2. Graph showing what factors are important to Canadians when choosing fresh produce

\subsection{Attitudes: New Brunswick}

Compared to Canada as a whole, respondents from New Brunswick were more likely to be willing to pay a premium for locally grown (meaning grown within the province, to New Brunswick respondents) CEA produce in the off-season. Over half (56.8\%) either agreed or strongly agreed with the statement "I would pay a premium for off-season fresh produce grown locally in greenhouses (or using other technologies) versus imported alternatives". Only $17.3 \%$ said that they would be unwilling to pay any kind of premium for locally grown produce, although $39.6 \%$ were willing to pay a premium greater than $10 \%$.

\section{How much of a premium are you willing to pay for locally grown fresh produce? $(n=220)$}

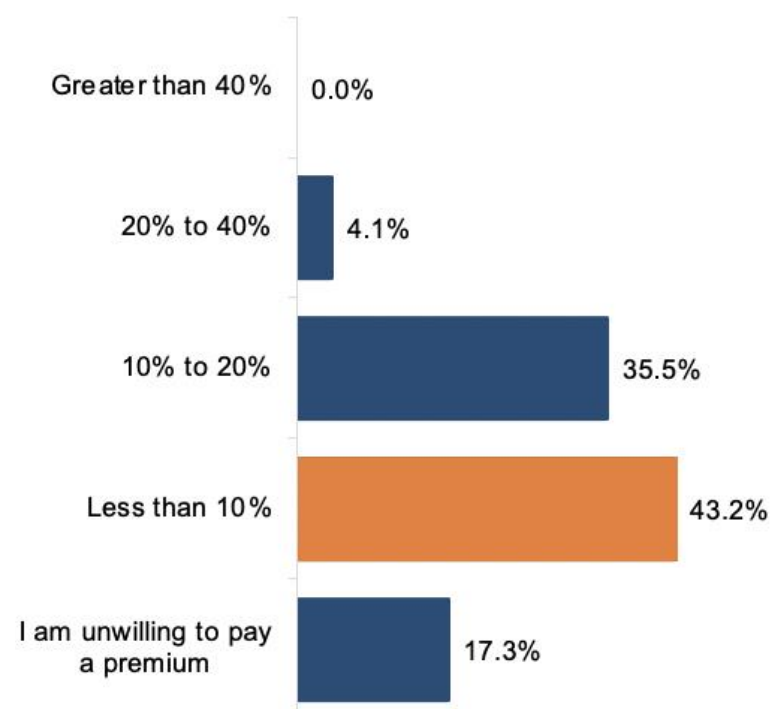

Figure 3. Graph showing how much of a premium New Brunswickers are willing to pay for fresh local produce 
Of the respondents, $27.7 \%$ said that CEA grown crops were better compared to $9.1 \%$ who said they were worse, which is slightly more positive than the rest of Canada. However, $73.2 \%$ of respondents said that price was important when choosing fresh produce, and while $37.3 \%$ said that where it was produced was important, it still trailed behind taste to which $40.9 \%$ it was important.

\section{Which of the following options are important to you when choosing fresh produce? (Please select all that apply) $(n=220)$}

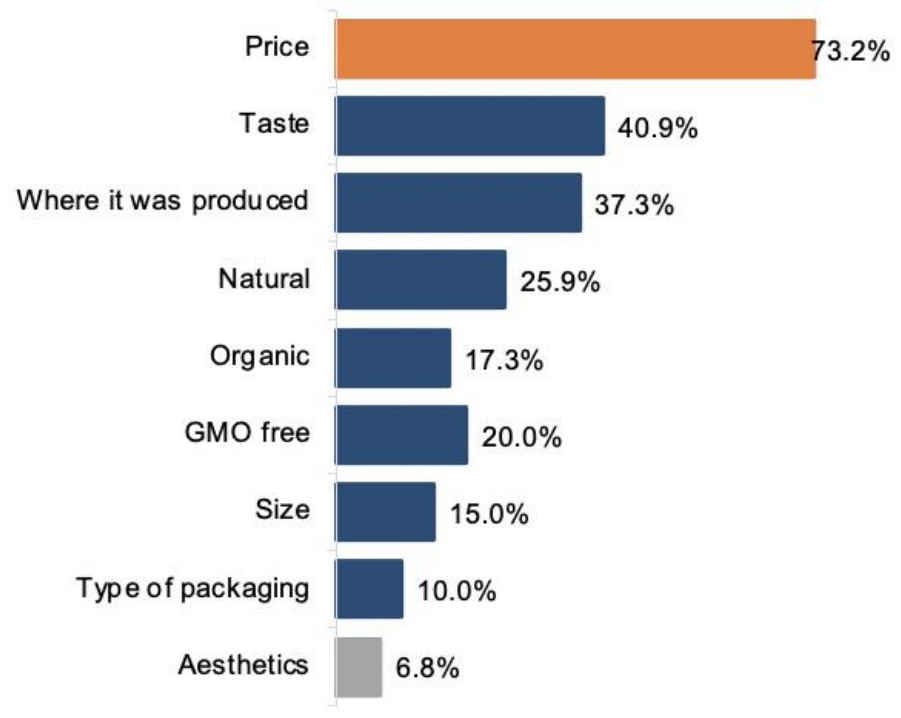

Figure 4. Graph showing what factors New Brunswickers consider important when choosing fresh produce

Compared to Canada as a whole, respondents from New Brunswick were even more likely to consider price important, though were also more likely to consider where something was grown.

\subsection{Implications of Attitudes}

Both Canadians as a whole and New Brunswickers in particular would be willing to pay extra money for locally grown produce over imported alternatives, and the premiums that they claim to be willing to pay are not insignificant. However, combined with the fact that the majority of respondents, both from New Brunswick and the rest of Canada, consider price to be an important factor when choosing groceries, this may not translate to people actually purchasing local produce. While many still consider where food was being grown to be important, it is only around half the amount that consider price important. This creates the paradox of people considering locally grown food to be more valuable but are neither looking for it nor necessarily willing to pay more for it. Though a significant percentage of respondents claim to be willing to pay more for greenhouse-grown produce in the off-season, this may not translate upon arriving at the grocery store with a strict budget. However, just because people consider price to be important that does not necessarily preclude them from ever paying more, they may still be willing to pay slightly more for certain things. Nevertheless, as most people are not considering where produce is grown as important, CEA grown crops do not have a major advantage when it comes to being grown locally. Instead, they are at an immediate disadvantage if they have a higher price tag, and consumers are not likely to be searching for food that is specifically locally grown.

\section{Grocery Shopping Habits}

In order to be viable, CEA grown crops need to reach consumers. This means being on the shelves where consumers are looking for them and overall availability to consumers. However, this also means dealing with regulations surrounding the food supply chain, such as additional fees charged to suppliers in an industry where margins are razor thin. In light of the pandemic, grocery store chains began building online infrastructure to serve their customers, and Loblaws, one of the major grocery store chains in Canada, has begun to pass the costs for this development onto their suppliers (see Appendix B). The fees charged to all of Loblaws suppliers are 
increasing by $1.36 \%$ as of January 3, 2021. Walmart is reportedly imposing similar fees on suppliers as well. This will not just affect the prices of any CEA grown crops, but all food. Consumers will absorb any increases in cost, increasing how much they pay for groceries on a regular basis, which may decrease their WTP. Any CEA start-ups will also need to consider where Canadians are buying their produce and the surrounding fees to guarantee that they can afford the extra costs associated with specific stores while also making sure that they can get their produce to consumers. CEA may not be able to be sold in certain places, like farmer's markets, who may have rules about who can set up a stall.

\subsection{Grocery Shopping Habits: Canada as a Whole}

When surveyed about where they get the majority of their fresh produce, $74.9 \%$ of respondents said that they got their produce at major grocery store chains. This would include chains such as Loblaws, Walmart, and Sobeys. Of the respondents who shop at major grocery stores for their fruits and vegetables, $88.3 \%$ either agreed or strongly agreed with the statement "Fruits and veggies are an important part of my household's diet" and $68.7 \%$ of respondents who shop at major grocery stores considered price to be an important factor when choosing what produce to buy. The next most common place for Canadians to buy produce was at farmer's markets, where $10.8 \%$ did their shopping, followed by small independent stores $(9.2 \%)$, people who grow their own produce (2.8\%), and people who shop at convenience stores (2.3\%).

\subsection{Grocery Shopping Habits: New Brunswick}

Compared to the rest of Canada, respondents from New Brunswick were less likely to shop at major grocery stores for their produce, with only 68.9\% saying that they bought most of their fruits and vegetables there. Of those who shopped at major grocery stores, $88.3 \%$ either agreed or strongly agreed with the statement "Fruits and veggies are an important part of my household's diet" and $74.4 \%$ of those shopping at major grocery stores considered price to be important. The next most common place to buy produce was at small independent grocery stores, where $17.1 \%$ of respondents bought their produce, then farmer's markets $(9.0 \%)$, people growing their own produce (3.2\%), and then convenience stores (1.8\%).

\subsection{Implications of Grocery Shopping Habits}

The vast majority of respondents said that they buy most of their produce at major grocery chains, meaning that any CEA suppliers will be subjected to any and all supplier fees charged by major grocery chains if they plan on reaching the majority of consumers. This potentially includes the $1.36 \%$ increase in supplier fees being charged by Loblaws and whatever fee increases that Walmart is imposing, which can impact profitability. While some smaller suppliers may be exempted from these fees, this is not a guarantee and the fact that suppliers need to play on major grocery chains' terms is incredibly important because most Canadians go to these stores and if CEA crops cannot be profitable in these stores because of the increased fees, then the majority of Canadians will not have access to the products, which would be detrimental to CEA's feasibility. Likewise, customers who go to major grocery chains are more likely on average to consider price to be an important factor when choosing what produce to buy. If CEA cannot compete on price with the rest of the products in the store and therefore is unprofitable for the store, the major grocery chains may stop working with the CEA suppliers.

New Brunswick has a larger percentage of respondents who go to independent grocery stores than Canadians as a whole, with $17.1 \%$ buying their produce there. While CEA suppliers may have better luck with smaller independent stores for negotiating fees, it is still less than one fifth of New Brunswickers, and not a very large market. They may be able to be profitable on those shelves, but the major grocery chains still have most of the consumers that CEA suppliers need to reach.

\section{Produce and Premiums}

Consumers who are willing to pay a premium for certain commodities may not be willing to pay more for other commodities. Certain crops are better suited to CEA than others, so it is important to assess what consumers do not want to pay a premium for, in case of a difference in price between CEA and conventionally grown crops. Consumers were asked what produce they were unwilling to pay a premium for and were able to respond with what they were unwilling to pay a premium for and write in their answer. As it was a respondent generated list, many of the produce types are not relevant to Canadian CEA concerns. Commonly grown CEA crops in Canada are bell peppers, cucumbers, tomatoes, and lettuce. Should consumers be unwilling to pay a potential premium on these commodities, CEA is immediately less viable because people will be more likely to flock to the cheaper options when presented with them.

\subsection{Produce and Premiums: Canada as a Whole}

Overall, $15.1 \%$ of respondents were least willing to pay a premium on strawberries, which was the highest result 
for all the produce provided, followed by $14.2 \%$ who were least likely to pay a premium on bananas. As for CEA crops, $11.1 \%$ were least likely to pay a premium on lettuce while $4.5 \%$ were least likely to pay a premium on peppers. Numbers were not provided for cucumbers and tomatoes, likely because there were an extremely small number of respondents who answered with those vegetables.

\subsection{Produce and Premiums: New Brunswick}

Of respondents from New Brunswick, 20.3\% were the least willing to pay a premium for strawberries, followed once again by bananas at $13.5 \%$. Of the CEA crops we collected data on, $10.8 \%$ were least willing to pay extra for lettuce and $4.5 \%$ were least willing to pay a premium for peppers.

\section{Which of the following fresh fruits and vegetables are you least willing to pay a premium on? $(n=222)$}

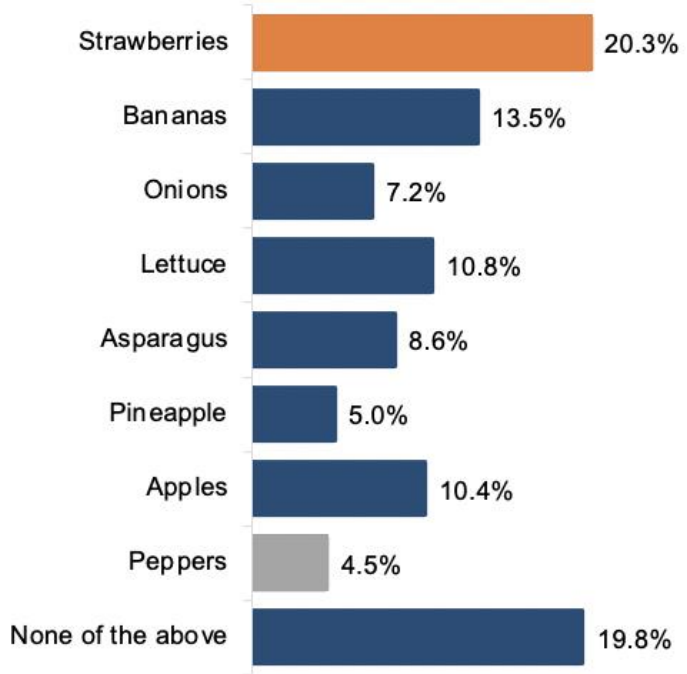

Figure 5. Graph showing what produce New Brunswickers are least willing to pay a premium for from a respondent generated list

\subsection{Implications of Produce and Premiums}

Fortunately for CEA suppliers, the majority of respondents were still willing to pay a premium on peppers. Respondents were less likely to be willing to pay a premium for lettuce, which is one of the more common greenhouse crops, which may pose a slight issue depending on what crops CEA producers choose to grow. Further market scans on how much of these products that consumers are buying would be valuable, to assess how much demand exists, but unfortunately there is little consumer data available for the grocery purchasing habits of Canadians.

\section{Conclusion}

The feasibility of CEA in New Brunswick will depend on a large variety of factors, some of which have no available data. However, from the information in the survey conducted, unless CEA crops are able to compete with conventionally grown and imported alternatives price-wise, it could face many issues in New Brunswick and Canada as a whole in light of the economic uncertainties surrounding COVID-19. Canadians were also surveyed specifically about paying a premium for food that they considered local, not necessarily Canada as a whole, and many of the larger regions in Canada, such as Ontario and Quebec, consider food grown within their region as local - a definition which would not include New Brunswick. The food security that CEA could provide would be beneficial not only in the province of New Brunswick but in other regions where similar market conditions can be found. It would be useful in preventing any uncertainties that come from wildfires, closing borders, droughts, and floods, but these solutions cannot only be made for short-term protections, they must be economically viable even in times when they are not needed, of which the biggest concern is price. Before making a decision on feasibility, the overall premium that would be charged to consumers for CEA crops and whether or not CEA suppliers can afford to make it into major grocery stores must be determined in light of consumer perceptions, WTP, and supplier profit margins. 


\section{References}

Abdullah, A., Al Enazi, S., \& Damaj, I. (2016, March). AgriSys: A smart and ubiquitous controlled-environment agriculture system. In 2016 3rd MEC International Conference on Big Data and Smart City (ICBDSC). IEEE. p. 1-6. https://doi.org/10.1109/ICBDSC.2016.7460386

Benke, K., \& Tomkins, B. (2017). Future food-production systems: vertical farming and controlled-environment agriculture. Sustainability: Science, Practice and Policy, 13(1), 13-26. https://doi.org/10.1080/15487733.2017.1394054

Deaton, B. J., \& Deaton, B. J. (2020). Food security and Canada's agricultural system challenged by COVID-19. Canadian Journal of Agricultural Economics, 68(2), 143-149. https://doi.org/10.1111/cjag.12227

Cavaliere, A., Ricci, E. C., Solesin, M., \& Banterle, A. (2014). Can Health and Environmental Concerns Meet in Food Choices? Sustainability (Basel, Switzerland), 6(12), 9494-9509. https://doi.org/10.3390/su6129494

Ceres Greenhouse Solutions. (2020). 2019 Global CEA Census Findings. Retrieved from https://ceresgs.com/2019-global-cea-census-findings/

Charlebois, S., Christensen, H. J., \& Hielm, S. (2015). Corporate philanthropy and channel impact in food security. British Food Journal, 117(2), 861-879. https://doi.org/10.1108/BFJ-01-2013-0003

Charlebois, S., T Vandertuin (2021). Food Safety Economics in the COVID-19 Pandemic, Journal of Food Research, 10 (4), DOI:10.5539/jfr.v10n4p1, 10 pages.

Chen, Z., An, C., Fang, H., Zhang, Y., Zhou, Z., Zhou, Y., \& Zhao, S. (2020). Assessment of regional greenhouse gas emission from beef cattle production: A case study of Saskatchewan in Canada. Journal of Environmental Management, 264, 110443. https://doi.org/10.1016/j.jenvman.2020.110443

Cholette, S., Özlük, Ö., Özşen, L., \& Ungson, R. G. (2013). Exploring purchasing preferences: Local and ecologically labelled foods. The Journal of Consumer Marketing, 30(7), 563-572. https://doi.org/10.1108/JCM-04-2013-0544

Culliford, A., \& Bradbury, J. (2020). A cross-sectional survey of the readiness of consumers to adopt an environmentally sustainable diet. Nutrition Journal, 19(1), 138. https://doi.org/10.1186/s12937-020-00644-7

Dieterle, J. M. (2016). Autonomy, Values, and Food Choice. Journal of Agricultural \& Environmental Ethics, 29(3), 349-367. https://doi.org/10.1007/s10806-016-9610-2

Fieldhouse, P., \& Thompson, S. (2012). Tackling food security issues in indigenous communities in Canada: The Manitoba experience. Nutrition \& Dietetics, 69(3), 217-221. https://doi.org/10.1111/j.1747-0080.2012.01619.x

Giraud, E. (2021). Urban Food Autonomy: The Flourishing of an Ethics of Care for Sustainability. Humanities (Basel), 10(1), 48. https://doi.org/10.3390/h10010048

Gómez, C., Currey, C. J., Dickson, R. W., Kim, H., Hernández, R., Sabeh, N. C., ... Burnett, S. E. (2019). Controlled Environment Food Production for Urban Agriculture. HortScience, 54(9), 1448-1458. https://doi.org/10.21273/HORTSCI14073-19

Haghiri, M., Hobbs, J., \& McNamara, M. (2009). Assessing consumer preferences for organically grown fresh fruit and vegetables in eastern New Brunswick. International Food and Agribusiness Management Review, 12(4).

Kolinjivadi, V., Mendez, A. Z., \& Dupras, J. (2019). Putting nature 'to work' through Payments for Ecosystem Services (PES): Tensions between autonomy, voluntary action and the political economy of agri-environmental practice. Land Use Policy, 81, 324-336. https://doi.org/10.1016/j.landusepol.2018.11.012

Laate, E. (2013). The Economics of production and marketing of greenhouse crops in Alberta. Alberta Agriculture and Rural Development. Retrieved from https://www1.agric.gov.ab.ca/\$department/deptdocs.nsf/all/agdex4369/\$file/821-59.pdf?OpenElement

Miliauskienė, J., Karlicek, Jr, R. F., \& Kolmos, E. (2021). Effect of Multispectral Pulsed Light-Emitting Diodes on the Growth, Photosynthetic and Antioxidant Response of Baby Leaf Lettuce ( Lactuca sativa L.). Plants (Basel), 10(4), 762. https://doi.org/10.3390/plants10040762 
Modongo, O., \& Kulshreshtha, S. N. (2018). Economics of mitigating greenhouse gas emissions from beef production in western Canada. Agricultural Systems, 162, 229-238. https://doi.org/10.1016/j.agsy.2017.12.008

Nikole, E. I., Laun, H., Brad, B., Scott, R., Kara, J. T., \& Brittany, G. (2020). Impact of Automated Controlled Environment Agriculture (CEA) Wheatgrass on Holstein Beef Performance \& Meat Quality. Journal of Animal Science, 98, 417. https://doi.org/10.1093/jas/skaa278.728

Power, E. (2008). Conceptualizing Food Security for Aboriginal People in Canada. Canadian Journal of Public Health, 99(2), 95-97. https://doi.org/10.1007/BF03405452

Shamshiri, R. R., Kalantari, F., Ting, K. C., Thorp, K. R., Hameed, I. A., Weltzien, C., ... Shad, Z. M. (2018). Advances in greenhouse automation and controlled environment agriculture: A transition to plant factories and urban agriculture. Int J Agric \& Biol Eng, 11(1), 1-22.

Skreli, E., Imami, D., Chan-Halbrendt, C., Canavari, M., Zhllima, E., \& Pire, E. (2017). Assessing consumer preferences and willingness to pay for organic tomatoes in Albania: A conjoint choice experiment study. Spanish Journal of Agricultural Research: SJAR, 15(3), E0114. https://doi.org/10.5424/sjar/2017153-9889

Walters, K. J., Lopez, R. G., \& Behe, B. K. (2021). Leveraging Controlled-Environment Agriculture to Increase Key Basil Terpenoid and Phenylpropanoid Concentrations: The Effects of Radiation Intensity and CO2 Concentration on Consumer Preference. Frontiers in Plant Science, 11, 598519. https://doi.org/10.3389/fpls.2020.598519

Wakefield, S., Fredrickson, K. R., \& Brown, T. (2015). Food security and health in Canada: Imaginaries, exclusions and possibilities. The Canadian Geographer, 59(1), 82-92. https://doi.org/10.1111/cag.12139

Watts, P., Koutouki, K., Booth, S., \& Blum, S. (2017). Inuit food security in canada: Arctic marine ethnoecology. Food Security, 9(3), 421-440. https://doi.org/10.1007/s12571-017-0668-0

Zheng, Y., Dixon, M. A., \& Ferguson, G. (2011). ORGANIC GREENHOUSE VEGETABLE PRODUCTION IN CANADA: CHALLENGES AND OPPORTUNITIES. Acta Horticulturae, 893, 1195-1200.

https://doi.org/10.17660/ActaHortic.2011.893.139

\section{Copyrights}

Copyright for this article is retained by the author(s), with first publication rights granted to the journal.

This is an open-access article distributed under the terms and conditions of the Creative Commons Attribution license (http://creativecommons.org/licenses/by/4.0/). 